\title{
Professional leadership for social work in state mental health services in Aotearoa New Zealand
}

\author{
David McNabb
}

David McNabb recently began the role of Head of Department - Social Practice, at Unitec, in Auckland. He was formerly the Professional Leader Social Work, Mental Health Services, Auckland District Health Board.

\begin{abstract}
This paper recounts the changes in the New Zealand government-run health services over the past 15 years and the subsequent changes to social work leadership in mental health services. Drawing on two pieces of local research, the article will explore social work mental health leadership in New Zealand. The first piece of research investigates the views of social work professional leaders (PL) about their roles and the prospects for social work in mental health in the future. The second piece of research investigates a new type of professional leadership role in the mental health services of the Auckland District Health Board. Clinical governance is an emerging phenomenon in health services internationally that is aimed at advancing quality improvement. This paper links developments in social work professional leadership with the activities of clinical governance in mental health services. It concludes that there is evidence of an improvement to the leadership infrastructure and of the contribution of leaders to clinical governance in district health boards (DHBs). However, many challenges remain for social work leaders into the future.
\end{abstract}

\section{Health services}

Government-funded health structures underwent a major period of change beginning in the late 1980s with a reconfiguration along commercial lines. This strengthened the role of managers and emphasised efficiency. These developments were criticised as being evidence of managerialism where the view of management prevailed over clinical and professional considerations. Professional leadership subsequently changed during this period with the demise of many social work managers and social work departments (Schofield, 2001; Woodward, 2001). Until the early 1990s the role of Chief Social Worker operated as the most senior social worker within each health service. The Area Health Boards' Chief Social Workers' Association was an active voice for social work and published documents on performance appraisal and competent health practice (Daniels, 1989 and 1989). These positions were subsequently disestablished. New Zealand government-funded health services are currently divided into 21 DHBs. 
In the Auckland District Health Board (ADHB ) mental health services the role of professional advisor emerged in the late 1990s as a half-time position, which it has continued to be to the present. Other New Zealand health services developed similar professional leadership roles (McNabb, 2001). This can be seen as a belated attempt to fill the professional leadership gap left by the deinstitutionalisation of mental health services that began in the 1980s and led to generic management of community-based services (Woodward, 2001). There has been limited planning and research associated with this change.

\section{Leadership}

Kouzes and Posner (1995) offer a broad-based and intensively researched text on leadership. Their five fundamental practices of exemplary leadership are: challenging the process, inspiring a shared vision, enabling others to act, modelling the way, and encouraging the heart. These practices bring together the main qualities of honesty, being forward looking, inspiring and being competent, and in combination these indicate credibility. Research on these leadership qualities were in order of preference as stated by practitioners. Leadership is defined as 'the art of mobilising others to want to struggle for shared aspirations' (Kouzes \& Posner, 1995, p. 30).

More recently there has been a renewed interest in social work leadership internationally and its response to the challenging social, cultural, economic and political environment. This is particularly so in the health context where social work has responded to the managerialist agenda by strengthening its leadership response (Mizrahi \& Berger, 2005; Lawler, 2007).

The PL role in most mental health services remains a leadership role without management responsibility for social workers. This paper supports the case that leaders have a key role to play in achieving effective outcomes for social work services.

\section{Professional leader role research}

Two pieces of research undertaken concerning social work leadership in New Zealand DHB mental health services provide support for an emphasis on effective leadership. The first project was undertaken in 2001 and engaged nine social work mental health leaders working in DHBs who completed questionnaires. A focus group was also conducted. Background information on the leaders and on the social workers in their services and their roles was gained to clarify the social work service context.

The work undertaken by each PL was similar. All recruited social workers, undertook performance management, undertook training, engaged in establishing professional standards, policy and quality projects relating to social work and to the wider organisation, and most engaged in salary setting. The make up of work undertaken by PL s remains constant with leaders also coordinating supervision, student placements and any intern programmes, coordinating salary progression procedures, and overseeing senior social worker roles. Leaders demonstrated a range of ways in which they fulfilled the five fundamental practices of exemplary leadership (Kouzes \& Posner, 1995).

Leaders were asked to describe the obstacles and opportunities they perceived for social work services in mental health. Analysis of responses was undertaken from the following 
themes: the social work profession, interprofessional relationships, the workforce, and the organisation and resourcing. Of the nine responses to the question of future changes four were negative, three were mixed or neutral and two were positive. This contrasted with responses to the earlier question on changes over the previous two years where six respondents were positive, two negative and one mixed. Overall the leaders presented a mix of caution and optimism about their role and for the future of social work services in mental health (McNabb, 2002).

\section{Professional Supervisor role research}

ADHB Mental Health Services appointed 'Professional Supervisors' in 2006 for the allied health professions of occupational therapy, psychology and social work. Pressure had come from increasing numbers of staff, higher expectations of meeting professional standards and the model of a similar role for allied health staff in the physical health setting known as Clinical Supervisor.

These positions were to support the existing PLs in occupational therapy, psychology and social work. Professional Supervisors were to focus on the staff within their profession and have a direct relationship with the managers of those staff. PLs were to focus on working with the relevant Professional Supervisors and with senior managers and other key relationships at a strategic level. It was planned to undertake an assessment of progress after one year. In 2007, 54 questionnaires each containing 17 quantitative and five qualitative questions about the role were sent to all mental health managers and Professional Supervisors, and a sample of randomly selected allied health clinicians. Nine questions related to performance on various criteria such as contribution to staff selection and recruitment; performance plans and training and development; participation in student placement and salary progression procedures.

Results showed all groups were positive about the Professional Supervisors' performance on different tasks, satisfied with the role on certain criteria and about the difference the role was making. Major themes in written responses included: time pressures; initial role confusion; benefits gained through professional advice; easier recruitment processes etc. Overall, even after a challenging start, within one year the roles appear to have benefited services and allied health professionals (Thorburn, McNabb and Rook, 2007).

\section{Clinical governance}

The ADHB has accepted the following definition of clinical governance: 'A framework through which organisations are accountable for continuously improving the quality of their services and safeguarding a high standard of care by creating an environment in which excellence in clinical care can flourish' (ADHB, 2007).

Clinical governance has been advanced the furthest in the United Kingdom from the late 1990s as a way to bridge managerial and clinical paradigms. In NZ the pursuit of quality improvement through effective clinical governance has been embraced by the DHBs and promoted as a way for the diverse range of interests in health services to work together (Perkins, Pelkowitz \& Seddon, 2006). Strong leadership is a component of clinical governance with an emphasis on clinician representation at its heart (Degeling, Maxwell, Iedema 
\& Hunter, 2004). Clinical governance incorporates the following clinical and professional activities: clinical audit and evaluation, peer review, establishing clinical indicators, addressing lessons from adverse events, consumer feedback, education and training, guidelines and pathways, process redesign, and service development (ADHB, 2007).

One of the responses by DHBs to the loss of allied health professional voices at the top level of the organisation has been to establish allied health structures. The first of these was the role of Director of Allied Health established at Auckland DHB in 2002. This has allowed allied health professions such as social work to have a direct link into the senior executive team and to be better represented in the Board-wide clinical governance process (Mueller \& Neads, 2005). Other DHBs are beginning to adopt a similar role of allied health leader but they are not all placed at the senior executive level.

\section{Social work leaders' organisation}

The Area Health Boards Chief Social Workers' Association had been disestablished in the early 1990s as the peak group for social work leaders. It was replaced by the national DHB Social Work Leaders Council that was launched in 2001. Leaders are representative of most of the 21 DHBs in New Zealand. The Council's terms of reference states that it seeks to be a national voice for health social work. Its role is to contribute at the national level to the wider clinical governance of the health sector. The Council does this through consultation with the DHBNZ (the coordinating body for DHBs), government health and education bodies, and the national social work bodies relating to registration, the profession and education.

The Council has drafted a practice framework for DHB social workers which is the first document it has developed (McNabb, 2008). It is hoped that this document will clarify and strengthen the voice of social work within DHBs and the wider social work sector. Various PLs have developed a social work mental health competencies document for their DHB (McNabb, Nes, \& Sharpe, 2006). The Council plans to develop a national social work competencies document.

\section{Discussion}

PL and supervisor roles have enhanced the ability of social work to establish standards, support practitioners, represent social work interests in the organisation and contribute to service development from a social work perspective. When these two roles are combined with the Director of Allied Health role, it allows social work to be represented at the three levels within ADHB of: practitioners, middle management and leadership, and the senior executive level. ADHB is committed to quality improvement through effective clinical governance. Social work now has the challenge of using the leadership structure in place to have a strong voice in the clinical governance process. It remains to be seen how well supervisors and those who support them can overcome the issues of time allocation, role clarity, training and key working relationships.

It would not be surprising to find PLs with a similar set of issues as a mixed view of the future of social work services within mental health was reported in 2001. It would be timely to update the views of this group on the future of social work services, also their demonstration of leadership attributes and a comparison with the issues raised by supervisors. 


\section{Conclusion}

Social work in the DHB mental health services in New Zealand should continue to explore ways of strengthening its leadership and thereby enhancing the contribution of social work in mental health. The combination of the roles described above strengthens the ability of the social work profession to have a strong voice in the DHB-wide clinical governance system. The combination of leadership roles and the clinical governance system is relatively new. It will require close attention from social work leaders to ensure the profession is adequately represented in DHB clinical governance.

The DHB Social Work Leaders Council is another important vehicle for social workers within DHBs to have a voice in national health and related forums. It meets as a total group once a year with four monthly regional meetings. Tele-conferencing is used for some of its working groups and it also uses group emailing. There is an honorary president with no secretariat or separate funding. Members of the Council have contributed to health policy development and to national DHB working parties on areas such as workforce development. The Council has taken several years to produce its first policy document and relies on the generosity of each Leader and their DHB. The effectiveness of the Council would be greatly enhanced by separate resources, perhaps through the DHBNZ organisation. The Council has grown during this decade and is well placed to have a stronger role in shaping DHB social work, particularly if it can access separate resources.

Further research on social work professional leadership and its role in meeting clinical governance requirements is required.

\section{References}

Auckland District Health Board. (2007). Clinical and professional governance ADHB. Auckland: Auckland District Health Board.

Daniels, K. R. (1989). Competent health social work. Christchurch, NZ: Social Work Department, University of Canterbury.

Daniels, K. (1989a). Performance appraisal of health social workers. Christchurch, NZ: Department of Social Work, University of Canterbury .

Degeling, P. J., Maxwell, S., Iedema, R., \& Hunter, D. J. (2004). Making clinical governance work. British Medical Journal, 329, 679-81.

Kouzes, J., \& B. Posner. (1995). The leadership challenge (2nd Ed.). San Francisco: Jossey-Bass.

Lawler, J. (2007). Leadership in social work: A case of caveat emptor? British Journal of Social Work, 37(1), $123-41$.

McNabb, D. (2001). DHB social work leaders' network. Auckland: Auckland District Health Board.

McNabb, D. (2002). Social work leadership in a changing mental health services District Health Board provider environment in New Zealand: Obstacles and opportunities in mental health social work. Auckland: Auckland District Health Board.

McNabb, D. (2002a). A strategy for effective social work within a state mental health service in Aotearoa/New Zealand. Social Work Review, 14(3), 13-17.

McNabb, D. (2008). Practice framework for social workers in District Health Board Provider Services Draft. Auckland: Auckland District Health Board.

McNabb, D., Nes, P., \& Sharpe, V. (2006). Competency framework for social workers in Mental Health Services. Auckland: Auckland Regional District Health Boards.

Mizrahi, T., \& Berger, C. S. (2005). A longitudinal look at social work leadership in hospitals: The impact of a changing health care system. Health $\mathcal{E}$ Social Work, 30(2), 155-65.

Mueller, J., \& Neads, P. (2005). Allied health and organisational structure: Massaging the organisation to facilitate outcomes. New Zealand Journal of Physiotherapy, 33(2), 48-54.

Perkins, R., Pelkowitz, A. \& Seddon, M. (2006). Quality improvement in New Zealand healthcare. Part 7: Clinical governance: An attempt to bring quality into reality. New Zealand Medical Journal, 19(1243), 1-7.

Schofield, V. (2001). Health social work. In M. Connolly (Ed.), New Zealand social work: Contexts and practice (pp. 146-156). Auckland: Oxford University Press. 
Thorburn, J., McNabb, D., \& Rook, D. (2007). One year of professional supervisors in Mental Health Services: A review of progress. Auckland: Auckland DHB.

Woodward, P. (2001). Mental health and social work. In M. Connolly (Ed.), New Zealand social work: Contexts and practice (pp.168-180). Auckland, NZ: Oxford University Press. 